\title{
ANALISIS FAKTOR YANG MEMPENGARUHI KEPUTUSAN PEMBERIAN KREDIT TERHADAP RESIKO NON PEFORMING LOAN (NPL) (STUDI KASUS PADA BANK MANDIRI CABANG S. PARMAN BENGKULU)
}

\author{
Veny Puspita, SE., MM \\ Fakultas Ekonomi Universitas Prof. Dr. Hazairin,SH \\ Email : Venypuspita2288@gmail.com
}

\begin{abstract}
Abstrak
Penelitian ini dilaksanakan dengan menggunakan metode survey, sumber data penelitian menggunakan data primer dan data sekunder. Data primer diperoleh dengan menyebarkan kuesioner dan data skunder di peroleh dari berbagai literature. Data yang dikumpulkan dianalisis dengan menggunakan metode kuantitatif analisis factor.

Berdasarkan hasil analisa data dapat disimpulkan bahwa ada 20 variabel yang diuji menunjukkan ada 17 variabel dan lima factor yang mempengaruhi pemberian kredit pada Bank Mandiri S Parman Bengkulu yaitu factor Individu Debitur, Factor Kemampuan Debitur, Factor Income, Factor Kekuatan dan Factor Risiko.

Sebagai saran, untuk mengurangi risiko tingginya nilai Rasio Non Peforming Loan (NPL) Pihak Pemberi Kredit dalam hal ini Perbankkan harus memahami dasar perkreditan yang sesuai dengan aturan dan kebijakan dalam penyaluran kredit. Pihak perbankkan harus jeli dalam menganalisa tentang calon debitur yang akan meminjam kredit.
\end{abstract}

Kata kunci : Faktor yang mempengaruhi pemberian kredit, Risiko Non Peforming Loan (NPL)

\section{Abstract}

This research was conducted using survey methods, research data sources using primary data and secondary data. Primary data is obtained by distributing questionnaires and secondary data obtained from various literature. The collected data were analyzed using quantitative method factor analysis.

Based on the results of data analysis, it can be concluded that there are 20 variables tested showing 17 variables and five factors that influence the granting of credit to Bank Mandiri Bengkulu Parman, namely individual Debtor factors, Debtor Ability Factors, Income Factors, Strength Factors and Risk Factors.

As a suggestion, to reduce the risk of a high value of the Non-Forming Loan (NPL) Ratio in this case, the Bank must understand the credit base in accordance with the rules and policies in lending. Banks must be observant in analyzing prospective borrowers who will borrow credit

Keywords: Factors that influence the provision of credit, Non-Peforming Loan Risk $(N P L)$ 


\section{PENDAHULUAN}

Bank merupakan lembaga keuangan yang salah satu usaha pokoknya memberikan kerdit dan jasa dalam lalulintas pembayaran dan peredaran uang. Kredit merupakan kepercayaan antara dua belah pihak yang mana kreditor percaya bahwa kredit itu tidak akan macet. Menurut (Bymont P. Kent, dikutip oleh Drs. Thomas Suyatno dkk, 1990: 15) kredit adalah hak untuk menerima pembayaran atau kewajiban untuk melakukan pembayaran pada waktu yang telah disepakati

Setiap usaha pasti memiliki risiko, resiko berhubungan dengan ketidakpastian karena kurang atau tidak adanya informasi mengenai apa yang terjadi. Risiko dalam pemberian keredit perbankkan terjadi karena kegagalan debitur dalam memenuhi kewajibannya yang telah disepakati bersama.

Kredit yang tidak tertagih akan menimbulkan masalah dalam laporan labarugi perbankan dan mampu mempengaruhi kinerja perbankkan. Non Peforming Loan (NPL) merupakan rasio yang digunakan dalam rangka mengukur kemampuan bank dalam mengcover risiko kegagalan dalam pemberian keredit kepada debitur. Pemberian suatu fasilitas kredit mengandung suatu resiko kemacetan, akibatnya kredit tidak dapat ditagih sehingga menimbulkan kerugian yang harus ditanggung oleh pihak Bank (Kasmir, 2005:128).

Semakin tinggi tingkat rasio Non Peforming Loan (NPL), maka semakin besar juga risiko yang akan ditanggung oleh pihak bank dan akan berpengaruh pada modal perbankkan, Besarnya Non Peforming Loan (NPL) menjadi salah satu penyebab sulitnya perbankan dalam menyalurkan kredit. Perkembangan dan persaingan dalam bisnis Perbankkan, membuat para pelaku bisnis ini untuk lebih berhati-hati dalam menyalurkan kreditnya

Oleh karena itu prinsip pemberian kredit kepada calon debitur harus menjadi perhatian khusus pihak perbankan. Berdasarkan latar belakang di atas maka penulis tertarik untuk mengangkat judul "Analisis Faktor yang mempengaruhi Keputusan Pemberian Kredit Terhadap Resiko Non Peforming Loan (NPL) (Studi Kasus pada Bank Mandiri Cabang S. Parman Bengkulu )

\section{Tujuan Penelitian}

Tujuan penelitian ini adalah untuk mengetahui faktor yang mempengaruhi keputusan pemberian kredit modal kerja terhadap resiko Non Peforming Loan? (Studi kasus pada Bank Mandiri Cabang S. Parman Bengkulu)

\section{Manfaat Penelitian}

Adapun manfaat dalam penelitian ini adalah :

1. Dapat digunakan oleh Perbankan khususnya Bank Mandiri sebagai acuan untuk meminimalisir terjadinya resiko Non Peforming Loan (NPL)

2. Penelitian ini diharapkan dapat menambah ilmu pengetahuan bidang manajemen Perbankan 


\section{Tinjauan Pustaka}

\section{Pengertian Bank}

Menurut undang-undang nomor 10 Tahun 1998 tentang perubahan atas undangundang Nomor 7 Tahun 1992 tentang Perbakkan, bank adalah badan usaha yang kegiatannya meghimpun dana dari masyarakat dalam bentuk simpanan dan menyalurkannya kembali ke masayarakat dalam bentuk kredit dan atau bentukbentuk lainnya dalam rangka meningkatkan taraf hidup rakyat banyak.

\section{Manajemen Kredit}

Menurut pasal 1 Ayat 11 Undang-undang Nomor 10 Tahun 1998 tentang Perubahan Undang-undang Nomor 7 Tahun 1992 tentang Perbankan, kredit adalah penyediaan uang atau tagihan yang disamakan dengan itu berdasrkan penetujuan atau kesepakatan pinjaman antara bank dengan pihak lain yang mewajibkan pihak peminjam untuk melunasi hutangnya setelah jangka waktu tertentu dan setelah pemberian bunga.

Kredit merupakan kesepakatan kedua belah pihak mengenai pelinasan hutang, bunga dan jangka waktu tertentu, dalam kredit ada penyerahan uang atau barang yang dapat menimbulkan tagihan kepada pihak lain dengan pinjaman ini bank berharap akan memperoleh sesuatu tambahan nilai pokok pijaman yang berupa bunga sebagai pendapatan bagi bank yang bersangkutan. Proses pemberian kredit ini berdasarkan pada suatu perjanjian yang saling percaya antara kedua belah pihak untuk memenuhi kewajiban masing-masing.

\section{Jenis-Jenis Kredit}

Saat ini jenis-jenis kredit yang dikeluarkan oleh perbankkan beragam jenisnya dan dapat dikelompokkan menjadi :

1. Jenis kredit menurut tujuannya

2. Kredit Berdasarkan jangka waktunya

3. Kredit berdasarkan macamnya

4. Kredit berdasarkan sector ekonomi

5. Kredit berdasarkan jaminan atau anggunan

6. Kredit berdasarkan golongan ekonomi debitur

7. Kredit berdasarkan status badan hukum debitur

8. Kredit berdasarkan sifat penggunaan dana

9. Kredit berdasarkan sumber dana

\section{Syarat- Syarat Pemberian Kredit}

Bank dalam menyalurkan kredit dengan harapan memperoleh keuntungan yang aman sekalugus mengemban tugas sebagai agen penyaluran dana (Intermediasi). Oleh karena itu, bank harus menerapkan prinsip kehati-hatian dalam menyalurkan bernagai jenis kredit yang diharapkan dapat melayani kebutuhan masyarakat.

Bank yang bertindak sebagai kreditur menerapkan dasar pertimbangan dalam menjamin kelancaran arus pengembalian kredit dan sebagai upaya menjaga 
kesetabilan perekonomian secara umum. (Kasmir, 2014) Syarat-syarat penyaluran kredit yang utama di kenal dengan prinsip 5 , yaitu sebagai berikut :

1. Charakter

Perisipnya penilaian karakter bertujuan mengetahui sejauhmana itikad baik dan kemampuan debitur dalam membayar kewajibannya. Aspek yang di nilai seperti kejujueran, kecerdasan, kesehatan, kebiasaan, dan tempramen.

2. Capacity

Capacity atau kapasitas penilaian atas kemampuan peminjam untuk mengelola usahanya dengan baik sehingga dapat menghasilkan laba ynag sesuai yang ditargetkan dan dapat memenuhi semua kewajibannya. Hal ini dapat dilihat dari kemampuan debitur di dalam bidang manajemen, keuangan, pemasaran dan pengelolaan usaha dengan menilai calon debitur.

3. Capital

Penilaian modal dapat dilihat apakah calon debitur dalam kegiatan usaha, perusahaan semakin memiliki daya tahan dalam menghadapi fluktuasi bisnis.

4. Colleteral

Collateral atau anggunan berfungsi sebagai pengamanan jika debitur tidak mampu membayar kewajibannya.

5. Condition of Ekonomy

Kondisi ekonomi merupakan keadaan perekonomian pada saat itu mempengaruhi keberadaan debitur. Meliputi variable makro baik dalam lingkup nasional atau internasional.

Selain prinsip $5 \mathrm{C}$ lembaga keuangan juga mempertimbangkan prinsip-prinsip pemberian kredit. Prinsip tersebut dikenal dengan istilah 7P yang meliputi sebagai berikut :

1. Personality, yaitu bank harus mengetahui keperibadian calon debitur seperti riwayat hidup dan keadaan keluarganya

2. Purpose, yaitu bank harus mengetahui tujuan atau keperluan dari pengguaan kredit

3. Prospect, yaitu bank harus mempertimbangkan harapan atau prospek usaha calon debitur pada masa mendatang

4. Payment, yaitu bank harus mengetahui calon debitur dalam pengembalian pinjaman.

5. Party, yaitu bank mengklasifikasikan debitur berdasarkan golongan-golongan tertentu

6. Profitability, yaitu bank harus mengetahui kemampuan calon debitur dalam menghasilkan laba.

7. Protection, yaitu bank menjaga atau melindungi kredit yang diberikan kepada debitur melalui jaminan barang atau asuransi

Selain menggunakan persyaratan kredit $5 \mathrm{C}$ dan $7 \mathrm{P}$ kredit yang disalurkan dinilai dari berbagai aspek tertagih dahulu. Penilaian seluruh aspek yang dikenal dengan 
studi kelayakan usaha umumnya dilakukan terhadap proyek-proyek yang besar dan jangka waktu panjang (long period) seperti :

1. Aspek hukum, ditujukan untuk mengetahui legalitas badan usaha yang menunjukkan kredit sehingga dapat diketahui apakah perusaahan benar ada atau fiktif

2. Aspek Pemasaran, menilai perkembangan permintaan konsumen terhadap produk yang dihasilkan sekarang dan prospek di masa yang akan datang.

3. Aspek Keuangan, berperan menilai sumber-sumber dana yang dimiliki untuk membiayai usaha dan penggunaan dana tersebut.

4. Aspek teknis operasional, membahas masalah teknik produksi . contoh kapasitas atau kemampuan mesin yang digunakan, lokasi usaha, keadaan ruang produksi atau ruang kerja dan jenis mesin yang digunakan.

5. Aspek manajemen, menilai struktur organisasi perusahaan, Sumber Daya Manusia yang dimiliki dan pengalaman perusahaan menangani proyek

6. Aspek social ekonomi, dampak kredit terhadap perekonomian

7. Aspek dampak lingkungan, menyangkut dampak proyek terhadap lingkungan baik di darat, sungai laui dan udara.

\section{Risiko Kredit Non Peforming Loan (NPL)}

Risiko kredit didefinisikan sebagai risiko kerugian yang terkait dengan kemungkinan kegagalan debitur memenuhi kewajibannya atau risiko bahwa debitur tidak membayar kembali utangnya. Untuk sebagian Bank, Risiko kredit merupakan risiko terbesar yang dihadapi. Pada umumnya, marjin yang diperhitungkan untuk mengantisipasi risiko kredit hanyalah merupakan bagian kecil dari total kredit yang diberikan bank dan oleh karnanya kerugian pada kredit dapat menghancurkan modal bank dalam waktu singkat. Penyebab utama terjadinya risiko pembiayaan adalah terlalu mudahnya bank memberikan pinjaman atau melakukan investasi karena terlalu dituntut untuk memanfaatkan kelebihan likuiditas, sehingga penilaian kredit kurang cermat dalam mengantisipasi berbagai kemungkinan risiko usaha yang dibiayainya yaitu risiko tingginya Rasio Non Peforming Loan (NPL)

Penelitian yang dilakukan oleh Chandra dewi dengan judul faktor-faktor yang mempengaruhi strategi pemberian kredit dan dampaknya terhadap non perfoming loan (studi kasus pada bank perkreditan rakyat di propinsi jawa tengah) menunjukkan ada empat variabel yang mempengaruhi keputusan pemberian kredit yaitu Kondisi Internal BPR, Kondisi Calon Debitur, kondisi lingkungan BPR, Strategi Pemberian Kredit, Kerjasama dengan pihak luar. 


\section{KERANGKA ANALISIS}

Berdasarkan tujuan penelitian dan kajian pustaka, maka disusun kerangka analisis untuk penelitian ini

Gambar 1.1 Kerangka Analisis

\begin{tabular}{|c|c|}
\hline Variabel Penelitian & Faktor \\
\hline $\begin{array}{ll}\text { 1. } & \text { Charakter } \\
\text { 2. } & \text { Capacity } \\
\text { 3. } & \text { Capital }\end{array}$ & $\begin{array}{l}\text { Pemberian } \\
\text { Kredit }\end{array}$ \\
\hline $\begin{array}{l}\text { 4. Colleteral } \\
\text { 5. Condition of Eknomy }\end{array}$ & \\
\hline 6. Personality & $\downarrow$ \\
\hline $\begin{array}{ll}\text { 7. } & \text { Purpose } \\
\text { 8. } & \text { Payment }\end{array}$ & Resiko NPL \\
\hline 9. Party & \\
\hline 10. Profitability & \\
\hline 11. Prospect & \\
\hline 12. Protection & \\
\hline 13. Aspek hukum & \\
\hline 14. Aspek Pemasaran & \\
\hline 15. Aspek Keuangan & \\
\hline 16. Aspek teknis operasional & \\
\hline 17. Aspek dampak lingkungan. & \\
\hline 18. Aspek manajemen & \\
\hline 19. Aspek social ekonomi & \\
\hline 20. Kerjasama dengan pihak luar & \\
\hline
\end{tabular}

\section{METODE PENELITIAN}

\section{Jenis dan Sumber Data}

Penelitian ini dilaksanakan dengan menggunakan metode survey, sumber data penelitian menggunakan data primer dan data sekunder. Data perimer diperoleh dengan menyebarkan kuisioner kepada responden. Sedangkan data skunder diperoleh dari berbagai leteratur.

2. Populasi dan Sampel

Populasi dalam penelitian ini adalah para pegawai Mikro Kredit Sales (MKS) yang bekerja di Bank Mandiri Cabang S. Parman Bengkulu yang berjumlah 112 orang dan semuanya diambil menjadi sampel dengan teknik non propability sampling yang dipilih adalah sampling jenuh

3. Teknik Pengumpulan Data

Pengumpulan data dalam penelitian ini menggunakan kuesioner yang disebarkan kepada responden. Pemberian skor dalam pengelolaan data menggunakan skala likert lima poin.

4. Teknik Analisis

Data yang telah dikumpulkan dianalisis dengan menggunakan metode kuantitatif analisis faktor. Dengan tahapan sebagai berikut : 1) Analisis distribusi frekuensi dari faktor -faktor yang dipilih. Analisis ini digunakan guna melihat gambaran 
secara umum dari setiap responden terhadap masing-masing indikator penelitian yang diberikan dalam kuesioner. 2). Analisis Faktor Menurut Malhotra (2004), analisis faktor merupakan bentuk analisa statistik multivariate yang digunakan untuk menemukan satu atau beberapa variabel konsep yang diyakini sebagai sumber yang melandasi seperangkat seperangkat variabel nyata. Analisis ini digunakan untuk menyederhanakan dan menentukan variabel nyata kedalam faktor-faktor tertentu sesuai dengan masing-masing indikator. Analisis faktor dilakukan dengan tahapan sebagai berikut : Menganalisis faktor-faktor yang akan dianalisis dan Menguji faktor-faktor tersebut menggunakan uji Bartlet Test of Spericty dan Measure of Sampling Adequncy (MSA). 3). Proses Faktoring, yaitu proses pemisahan variabel-variabel yang memenuhi korelasi dari nilai MSA sebelumnya menjadi suatu kelompok/ grup tertent, umumnya metode yang digunakan dalam proses factoring adalah principal components analisis (PCA) atau analisis komponen utama (AKU). 4) Proses Rotasi, dalam proses factoring biasanya masih terdapat variabel-variabel yang belum mempunyai posisi yang jelas dalam suatu kelompok/ group faktor. Proses rotasi ini untuk memperjelaskan posisi variabel-variabel yang dianalisis tersebut dalam kelompok factor, dan 5) Interprestasi penamaan faktor yang terbentuk.

\section{ANALISIS}

Dari hasil pengolahan data yang dilakukan menunjukan bahwa antar variabel telah menunjukan korelasi yang signifikan, hal ini dapat dilihat dari nilai bartlett's test of sphericty yang mempunyai nilai sign $<$ Alpha $5 \%(0,000<0,005)$

Tabel 2.1

\section{KMO and Bartlett's Test}

\begin{tabular}{llr}
\hline Kaiser-Meyer-Olkin Measure of Sampling Adequacy. & .864 \\
\hline Bartlett's Test of Sphericity & Approx. Chi-Square & 2210.954 \\
\cline { 2 - 3 } & Df & 190 \\
\cline { 2 - 3 } & Sig. & .000 \\
\hline
\end{tabular}

Hasil olah data

\section{Matrik Korelasi}

Selain itu pada nilai kaiser meyer olkin (MSA) menunjukan nilai 0.864 dimana nilai ini lebih besar dari 0.5 sehingga model analisis faktor ini berarti sudah terjadi korelasi yang signifikan, juga dapat dilanjutkan ke tahap berikutnya. Pada Tabel Anti Image Matrix, khususnya pada bagian Anti Image Correlation menunjukan kaiser meyer olkin (MSA) dari masing-masing variabel yang diteliti. Berikut Nilai kaiser meyer olkin (MSA) masing- masing variabel yang menunjukan bahwa variabel tersebut mempengaruhi keputusan pemberian kredit 
Tabel 2.2

Skor Nilai Yang Mempengaruhi Keputusan Pemberian Kredit

\begin{tabular}{|l|c|}
\hline \multicolumn{1}{|c|}{ Variabel Penelitian } & Nilai MSA pada Anti- Imange Corelation \\
\hline Carakter & 0.893 \\
\hline Capacity & 0.897 \\
\hline Capital & 0.869 \\
\hline Colleteral & 0.863 \\
\hline Condition of Ekonomi & 0.948 \\
\hline Personality & 0.858 \\
\hline Purpose & 0.840 \\
\hline Payment & 0.891 \\
\hline Party & 0.842 \\
\hline Profitability & 0.841 \\
\hline Prospect & 0.303 \\
\hline Protection & 0.890 \\
\hline Aspek Hukum & 0.931 \\
\hline Aspek Pemasaram & 0.855 \\
\hline Aspek Keuangan & 0.919 \\
\hline Aspek Teknis Operasional & 0.925 \\
\hline Aspek Dampak Lingkungan & 0.366 \\
\hline Aspek Manajemen & 0.831 \\
\hline Aspek Sosial Ekonomi & 0.820 \\
\hline Kerjasama dengan pihak luar & 0.289 \\
\hline
\end{tabular}

Sumber oleh data

Dapat dilihat dari Tabel 1.2 bahwa dari 20 variabel yang diuji menunjukkan bahwa ada tiga variable yang tidak memenuhi factor yang mempengaruhi pemberian kredit pada Bank Mandiri Cabang S Parman Bengkulu dengan nilai Anti Images Matrices terlihat nilai MSA kurang dari 0.5 yaitu (1) variable prospect hal ini disebabkan karena variable ini hanya berlaku bagi nasabah yang akan mengajukan pinjaman kredit untuk modal usaha atau bisnis dengan nilai MS A pada Anti- Imange Corelation 0.303 (2) variable aspek dampak lingkungan dengan nilai MSA pada Anti- Imange Corelation 0.366 dan variabel Kerjasama dengan Pihak luar dengan nilai MSA pada Anti-Imange Corelation 0.289. dengan demikian ketiga factor tersebut harus dikeluarkan karena tidak memenuhi kriteria yang menunjukkan hubungan erat, sehingga analisis factor dapat dilakukan dengan 17 faktor yang mendukung.

2. Penentuan jumlah faktor

Dalam menentukan jumlah faktor dapat didasarkan pada eigen value dan percent of variance. Jika didasarkan pada eigen value, suatu faktor dapat menjadi pertibangan pemberian kredit jika memiliki nilai $>1.0$. Jika berdasarkan percent of variance suatu faktor dapat menjadi pertimbangan 
memiliki nilai $>5 \%$, sehingga apabila terdapat faktor -faktor yang memiliki presentase varian di atas 5\%, maka fakor tersebut ditahan dalam model.

Berdasarkan analisis dengan metode komonen prinsip pada initial statistik ditujukan bahwa terdapat lima faktor yang menjadi dasar keputusan pemberian kredit pada Bank Mandiri Cabang S Parman Bengkulu

\section{Rotasi Faktor}

Dari hasil analisis penentuan jumlah faktor, menunjukan bahwa dari 19 variabel yang dianalisis dikelompokkan menjadi lima fektor yaitu factor individu debitur, faktor kemampuan, faktor income, faktor kemampuan debitur dan faktor risiko

Tabel 2.3

Rotasi Faktor Keputusan Pemberian Kredit

\begin{tabular}{|c|c|c|c|c|c|}
\hline No & Faktor & Variabel & $\begin{array}{l}\text { Total } \\
\text { Eigen } \\
\text { Value }\end{array}$ & $\begin{array}{c}\% \text { of } \\
\text { variance }\end{array}$ & $\begin{array}{c}\text { Cumulative } \\
\%\end{array}$ \\
\hline \multirow[t]{4}{*}{1} & \multirow{4}{*}{$\begin{array}{l}\text { Faktor } \\
\text { Individual } \\
\text { Debitur }\end{array}$} & Carakter & 0.893 & \multirow[t]{4}{*}{50.870} & \multirow[t]{4}{*}{50.870} \\
\hline & & Personality & 0.858 & & \\
\hline & & Purpose & 0.840 & & \\
\hline & & Party & 0.842 & & \\
\hline \multirow[t]{3}{*}{2} & \multirow{3}{*}{$\begin{array}{l}\text { Faktor } \\
\text { Kemampuan } \\
\text { debitur }\end{array}$} & Capacity & 0.897 & \multirow[t]{3}{*}{8.231} & \multirow[t]{3}{*}{59.101} \\
\hline & & Payment & 0.891 & & \\
\hline & & Aspek Keuangan & 0.919 & & \\
\hline \multirow[t]{3}{*}{3} & \multirow{3}{*}{$\begin{array}{l}\text { Faktor } \\
\text { Income }\end{array}$} & Profitability & 0.841 & \multirow[t]{3}{*}{6.776} & \multirow[t]{3}{*}{65.878} \\
\hline & & Aspek Pemasaran & 0.855 & & \\
\hline & & Aspek Sosial Ekonomi & 0.820 & & \\
\hline \multirow[t]{4}{*}{3} & \multirow{4}{*}{$\begin{array}{l}\text { Faktor } \\
\text { Kekuatan }\end{array}$} & Capital & 0.869 & \multirow[t]{4}{*}{5.871} & \multirow[t]{4}{*}{71.749} \\
\hline & & Coleteral & 0.863 & & \\
\hline & & Aspek Operasional & 0.925 & & \\
\hline & & Aspek Manajemen & 0.831 & & \\
\hline \multirow[t]{3}{*}{3} & \multirow{3}{*}{$\begin{array}{l}\text { Faktor } \\
\text { Risiko }\end{array}$} & Condition of Ekonomi & 0.948 & \multirow[t]{3}{*}{5.116} & \multirow[t]{3}{*}{76.865} \\
\hline & & Protection & 0.890 & & \\
\hline & & Aspek Hukum & 0.931 & & \\
\hline
\end{tabular}

Sumber oleh data

Semakin tinggi nilai eigen value menunjukan bahwa pembentukan faktor semakin baik karena kontribusi kelompok variabel yang mendasari menunjukan perbedaan tersendiri dengan faktor-faktor lainnya. Dengan metode ekstraksi prinsipal component analysis (total expained, rotated component matrix), hasil rotasi terlihat dalam Tabel 2.3 


\section{Interprestasi Faktor}

Dari hasil rotasi faktor ditetapkan 19 variabel yang dianalisis lebih lanjut yang kemudian dilakukan pemilihan menjadi lima faktor yaitu sebagai berikut :

a. Faktor 1 (Individu Debitur)

Faktor utama dinamai dengan Faktor Individu debitur karena variabel yang ada didalamnya mencerminkan berbagai bagian individu calon debitur. Faktor ini juga yang paling mendasari keputusan pemberian kredit. Faktor ini mempunyai eigen value sebesar 50.870 dengan empat variabel yang membentuknya yaitu carakter, personality, purpose, dan party

b. Faktor 2 (Kemampuan debitur)

Faktor ke dua dinamai faktor kemampuan debitur karena variabel yang ada didalamnya mencerminkan faktor kemampuan calon debitur dalam mengelola usahanya, mengembalikan pinjaman, dan membiayai usahanya. Faktor ini menjadi pertimbangan dalam pemberian kredit dengan eigen value sebesar 8.231 dan memiliki tiga variabel yang membentuknya yaitu Capasity, Payment dan Aspek Keuangan.

c. Faktor 3 (Income)

Faktor yang ke tiga dinamai Faktor Income karena faktor ini terbentuk dari empat variabel yaitu Provitability, Aspek Pemasaran, dan Aspek social ekonomi, dengan eigen value sebesar 6.776

d. Faktor 4 (Kekuatan)

Faktor yang ke empat dinamai Faktor kekuatan karena faktor ini terbentuk dari empat variabel yaitu Capital, Coleteral, Aspek Manajemen dan aspek Operasional, dengan eigen value sebesar 5.871

e. Faktor 5 (Risiko)

Faktor yang ke lima dinamai Faktor Risiko karena faktor ini terbentuk dari tiga variabel yaitu Condition Ekonomi, protection dan Aspek Hukum dengan eigen value sebesar 5.116

\section{KESIMPULAN DAN SARAN}

Berdasarkan penelitian dengan pengujian data dapat disimpulkan bahwa :

a. Faktor Individu Debitur

Faktor individu debitur utama ini factor yang paling mendasari keputusan pemberian kredit. Faktor ini mempunyai eigen value sebesar 50.870 dengan empat variabel yang membentuknya yaitu carakter, personality, purpose, dan party

b. Faktor Kemampuan Debitur

Faktor Kemampuan debitur ini menjadi pertimbangan dalam pemberian kredit dengan eigen value sebesar 8.231 dan memiliki tiga variabel yang membentuknya yaitu Capasity, Payment dan Aspek Keuangan. 
c. Faktor Income

Faktor Income terbentuk dari tiga variabel yaitu, Provitability, Aspek Pemasaran, dan Aspek social ekonomi, dengan eigen value sebesar 6.776

d. Faktor Kekuatan

Faktor kekuatan karena faktor ini terbentuk dari empat variabel yaitu Capital, Coleteral, Aspek Manajemen dan aspek Operasional, dengan eigen value sebesar 5.871

e. Faktor 5 Risiko

Faktor Risiko karena faktor ini terbentuk dari tiga variabel yaitu Condition Ekonomi, protection, dan Aspek Hukum, dengan eigen value sebesar 6.776

\section{Saran}

1. Untuk mengurangi risiko tingginya nilai Rasio Non Peforming Loan (NPL) Pihak Pemberi Kredit dalam hal ini Perbankkan harus memahami dasar perkreditan yang sesuai dengan aturan dan kebijakan dalam penyaluran kredit. Pihak perbankkan harus jeli dalam menganalisa tentang calon debitur yang akan meminjam kredit

2. Perbankkan harus memahami factor-faktor pemberian kredit agar pihak perbankkan memperoleh keyakinan terhadap kemampuan dari calon debitur yang akan meminjam kredit kepada pihak perbankkan untuk memenuhi kewajibannya kepada bank secara tertib sesuai dengan perjanjian yang telah disepakati bersama.

\section{DAFTAR PUSTAKA}

Dewi Chandra, Faktor-faktor yang mempengaruhi Strategi Pemberian kredit dan dampaknya terhadap Non Performing Loan (studi Kasus pada Bank Perkreditan Rakyat di Provinsi Jawa Tengah. Tesis 2009

Kasmir, Bank dan Lembaga Keuangan Lainnya. Jakarta : Rajawali PT. Raja Grafindo Persada. 2005

--------, Dasar-dasar Perbankan Edisi Revisi. Jakarta : Raja Grafindo Persada. 2014

Malhotra, N.K. Marketing Research - An Applied Orientation. New Jersy: Person Education, Inc. 2004

Suyatno Thomas, Dkk, Dasar-dasar Perkreditan; Gramedia: Jakarta 1990

Undang-Undang Nomor 10 Tahun 1998 tentang Perubahan Undang-Undang Nomor 7

Tahun 1992 tentang Perbankan dan Penjelasanny 